\title{
Loss Carved in Coastal Waters
}

\author{
after "Raven in the Pink" by James Schoppert
}

for Kristina Miller, in memory of her brother, Alex

In the Museum of the North, an imperceptible breeze from Schoppert's carving upwells cold, nutrient-rich waters.

Curtains of light through skies and seas

blur the horizon between real and reflection.

Outstretched hands from earth and water are fed here.

Alex's hunger was deeper than an ocean could satisfy.

Trickster eyes gaze down, searching for something more.

Is there just one raven?

Are other eyes illusions?

Wings make indigo strokes

in pastel morning skies.

Aligning with dim panels of light, you swim alone through chop, where you struggle to breathe and swallow salt water as surf breaks over your loss.

Your brother flew away without warning.

Raven in the pink. 